\title{
Design and Characterization of the Material Attributes of a Co-processed Excipient Developed for Direct Compression Tableting
}

\author{
Yonni Apeji1, 2*, Fatima Haruna², Avosuahi Oyi², Adamu Isah², Teryila Allagh² \\ 1 National Institute of Pharmaceutical Education and Research (NIPER), Department of Pharmaceutics, Sector 67, S.A.S \\ Nagar, Punjab 160 062, India. \\ 2 Ahmadu Bello University, Faculty of Pharmaceutical Sciences, Department of Pharmaceutics and Industrial Pharmacy, \\ Zaria, Kaduna State, Nigeria.
}

\section{ABSTRACT}

The objective of the study was to characterize the material attributes of a co-processed excipient and determine its suitability for tableting applications.

A single composite excipient named SGS consisting of tapioca starch (TS), gelatin (GEL) and colloidal silicon dioxide (CSD) was developed by co-processing using the method of co-fusion and its solid-state, powder and mechanical properties evaluated.

Particle morphology revealed spherical shaped particles of SGS with slightly rough surfaces. PXRD was characterized by a halo diffraction pattern consistent with amorphous materials. FT-IR studies demonstrated drug-excipient compatibility. Flow properties of SGS improved in relation to its physical mixture (SGS-PM) and the mechanical properties of SGS was enhanced as a result of co-processing. The outcome of the study demonstrates the suitability of SGS as a tableting excipient.

Keywords: Material attributes, starch, co-processed excipient, tableting

\section{INTRODUCTION}

In the formulation of tablets, excipients play a crucial role in ensuring the smooth processing, formation and robust performance of the dosage form. They have been rightly referred to as functional components of a formulation because they influence the manufacturability, stability, bioavailability and

*Corresponding Author: Yonni Apeji, e-mail: yeapeji@abu.edu.ng Yonni Apeji ORCID Number: https://orcid.org/0000-0002-3116-7570 Fatima Haruna ORCID Number: https://orcid.org/0000-0001-5540-8212 Avosuahi Oyi ORCID Number: https://orcid.org/0000-0002-6232-425X Adamu Isah ORCID Number: https://orcid.org/0000-0003-4913-1186 Teryila Allagh ORCID Number: https://orcid.org/0000-0002-5814-3499 (Received 16 May 2019, accepted 13 July 2019) 
safety of the formulation ${ }^{1}$. Depending on the composition of the formulation, excipients may constitute more than $50 \%$ of the entire formulation. They have been used actively as diluents, binders, disintegrants, glidant, lubricants, colorants etc.2-4 Due to the functional role of excipients in tablet formulation, it is imperative to continually expand the range of excipients available to the pharmaceutical industry to accommodate the diverse challenges encountered in the formulation of novel drug molecules.

Currently, direct compression (DC) method of tablet formulation is gaining much space among manufacturers because it is less demanding, cost effective and does not require much labour when compared to other methods of tableting like wet granulation ${ }^{5,6}$. Nevertheless, the successful processing of formulations containing drugs into tablets by direct compression rests solely on the robustness of the DC excipient employed. DC excipients are required to impart the critical attributes of flowability and compressibility to a formulation to ensure a smooth tableting process that will yield tablets of acceptable quality. Other attributes like solid-state properties and compaction behaviour can influence the functionality of DC excipients in tablet formulation ${ }^{7,8}$. Hence, it has become necessary to develop DC excipients that will fulfil the demands of a robust tableting process.

The concept of developing novel excipients with improved functionality by coprocessing has been the focus of several researchers in the last few decades. It is a process where two or more excipients are combined at sub-particle level in optimized proportions using a suitable method to yield a single composite excipient that integrates the advantages of the interacting excipients while minimizing their limitations ${ }^{5,9-12}$. The rationale for co-processing two or more excipients takes into consideration the material properties of the interacting excipients. This factor is crucial because the functionality of the co-processed excipient is determined by the material attributes of the individual excipients. Many studies have been carried out by researchers to co-process excipients including starches, celluloses, gums, chitin and other traditional excipients ${ }^{13-17}$. In our study, native tapioca starch (TS) was co-processed with gelatin (GEL) and colloidal silicon dioxide (CSD) for consideration as a multifunctional excipient in DC formulations. Native starches are inherently weak with poor flow and compression properties ${ }^{18}$. Hence, they are not recommended for DC method of tablet formulation. To enhance the binding properties of TS, GEL has been incorporated to fortify its structural strength. CSD has been used traditionally as a glidant in tablet formulations ${ }^{19}$. Other pharmaceutical applications of CSD as a dispersing agent, suspending agent, emulsion stabilizer, adsorbent and 
viscosity controlling agent have been documented in literature ${ }^{20}$. As a glidant, CSD has been added as part of the composition of the co-processed excipient to enhance its flowability. Several studies have shown that the deposition of CSD on particle surfaces during the process of silicification has generated materials with improved functionality relating to disintegration, mechanical resistance and tablet strength ${ }^{21-23}$. Hence, the inclusion of CSD in the formation of the co-processed excipient will enhance the overall performance of the excipient in tablet formulation. Tapioca starch was selected for this study as an alternative to corn starch that has been widely used as a tablet excipient in drug manufacturing. Among the starchy staples, tapioca gives a carbohydrate production which is about $40 \%$ higher than rice and $25 \%$ superior to corn, making tapioca the cheapest source of calories for both human nutrition and animal feeding ${ }^{25}$. It can be obtained in commercial quantities from the root crop of Manihot esculenta Crantz grown around the world particularly in Sub-Saharan Africa, Southeast Asia and Latin America but is yet to be fully harnessed by the pharmaceutical industry.

To date, there is yet to be any co-processed excipient that has been developed containing these three excipients. The solid-state, powder and compaction properties of SGS were characterized to evaluate its potential as a multifunctional excipient in direct compression tableting.

\section{METHODOLOGY}

\section{Materials}

Tapioca starch was obtained as a gift sample from Quality Starch and Chemicals (Tamil Nadu, India), Gelatin (May and Baker Ltd, England), Colloidal silicon dioxide (Cab-o-Sil ${ }^{\circledR}$, Cabot GmbH, Germany), Ibuprofen (Himedia laboratories Ltd, Mumbai, India). All other materials used were of analytical grade.

\section{Preparation of the co-processed excipient}

The co-processed excipient code-named $S G S$ was prepared using the method described by Adeoye and Alebiowu ${ }^{26}$. Tapioca starch (90 g) was dispersed in distilled water to obtain a $40 \%{ }^{\mathrm{w}} / \mathrm{w}$ suspension and mixed with corresponding quantities of gelatin (7.5 g) and colloidal silicon dioxide (2.5 g) for 5 min. Further mixing continued in a shaker water bath (Julabo SW 23, Seelbach, Germany) set to rotate at a speed of $60 \mathrm{rpm}$ and temperature of $54 \pm 2{ }^{\circ} \mathrm{C}$ for 15 min. The mixture was homogenized for $5 \mathrm{~min}$ at a speed of 11,000 rpm (Ultra Turrax $\mathrm{T} 25$ basic Ika ${ }^{\circledR}$ Werke, India), followed by air-drying initially at room temperature $\left(25 \pm 2{ }^{\circ} \mathrm{C}\right)$ for $2 \mathrm{~h}$ and then drying completed in the Fluid bed dryer (Retsch TG 100, Germany) at $40^{\circ} \mathrm{C}$ for $10 \mathrm{~min}$. The powder obtained was 
passed through a sieve of $500 \mu \mathrm{m}$, packed into tight sealed containers and kept in the desiccator containing phosphorous pentoxide $\left(\mathrm{P}_{2} \mathrm{O}_{5}\right)$ for further studies.

\section{Optical and polarized microscopy}

Optical and polarized microscopy of the powder samples were performed with Leica DMLP polarized microscope (Leica Microsystems Wetzlar GmbH, Germany). The images obtained were captured with a JVS colour video camera and analysed using Linksys 32 software. Particle size analysis was carried out by measuring diameter along the longest axis of a minimum of 500 particles for each sample and the $d_{10}, d_{50}$ and $d_{90}$ parameters reported.

\section{Scanning electron microscopy (SEM)}

Particle morphology of powder samples were observed under a scanning electron microscope (S-340o, Hitachi Ltd., Tokyo, Japan) operated at an excitation voltage of $10 \mathrm{kV}$. The powder samples were mounted onto a steel stage using double sided adhesive tape and coated with gold using ion sputter (E1010, Hitachi Ltd., Japan). Thereafter, SEM images of powder samples were captured at various magnifications.

\section{Powder X-ray diffraction (PXRD)}

PXRD analysis of powder samples were recorded at room temperature on Bruker's D8 advance diffractometer (Bruker, Germany) with $\mathrm{Cu}$ Ka radiation (1.54 $\AA$ ), at $40 \mathrm{kV}, 40 \mathrm{~mA}$ passing through nickel filter. Analysis was performed in a continuous mode with a step size of $0.01^{\circ}$ and step time of $1 \mathrm{~s}$ over an angular range of $2-40^{\circ} \mathbf{2}$, using zero background holder. The obtained diffractograms were analysed with DIFFRAC plus EVA (ver.9.0) diffraction software.

\section{Fourier transform infrared spectroscopy (FT-IR)}

The FT-IR spectra of all powder samples were recorded from 4000 to $650 \mathrm{~cm}^{-1}$ on Perkin Elmer Spectrum 400 spectrometer. Drug-excipient compatibility studies was carried out by running an IR scan of the physical mixture of ibuprofen and SGS in a 1:1 ratio. Analysis of FT-IR spectra was performed using Spectragryph-optical spectroscopy software (ver. 1.2).

\section{True density}

The method of helium pycnometry (Pycno 30, Smart Instruments, India) was used to measure the true density of powder samples at $25 \pm 2{ }^{\circ} \mathrm{C} / 40 \pm 2 \% \mathrm{RH}$. The data was collected in triplicate and the mean \pm SD was recorded. 


\section{Bulk density, Tapped density, Carr's index and Hausner's ratio}

Bulk and tapped density parameters for each powder sample were determined according to the USP II method ${ }^{27}$. Carr's index (CI) and Hausner's ratio (HR) were calculated based on equations $1 \& 2$ using a minimum of three replicates.

$$
\begin{aligned}
& \mathrm{CI}=\frac{\mathrm{TD}-\mathrm{BD}}{\mathrm{TD}} \times 100 \% \ldots \ldots \ldots \ldots \ldots . . \mathrm{Eq} .1
\end{aligned}
$$

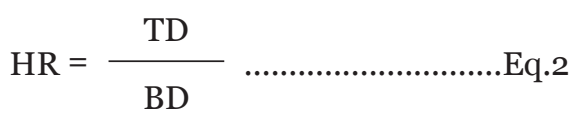

\section{Angle of repose (AR)}

The flow properties of powder samples were assessed by measuring the angle of repose using the granulate flow tester (GTB, Erweka, Germany). Twenty grams (20 g) of the sample powder was poured into the stainless-steel funnel and allowed to flow out through the orifice measuring $10 \mathrm{~mm}$ in diameter unto a plate with specified surface forming a cone of powder. The side wall of the built-up cone was measured using an integrated driven laser and the actual angle of repose was calculated and displayed. The experiment was repeated three times and the average recorded $(n=3)$.

\section{Heckel and Kawakita analysis}

Powder compacts for each sample were obtained by compressing $400 \mathrm{mg}$ powder weighed individually on a Hydraulic press (Model 3912, Carver Inc., USA) at pressures ranging from $35-250 \mathrm{MPa}$ using a $13 \mathrm{~mm}$ flat-faced circular punch and die set at a dwell time of $30 \mathrm{~s}$. A minimum of three tablets were compressed at each pressure. The tablets were kept in the desiccator containing phosphorous pentoxide $\left(\mathrm{P}_{2} \mathrm{O}_{5}\right)$ for $24 \mathrm{~h}$ to allow for elastic recovery prior to analysis. The thickness and diameter of the tablets were measured using a digital micrometre screw gauge (Mitutoyo, Japan). The following parameters were calculated for each tablet: volume, apparent density, relative density and porosity. The data obtained were fitted into the Heckel and Kawakita equations to generate plots used to characterize the compaction profile of the powder samples.

The Heckel model ${ }^{28}$ shows the densification of the powder bed during compaction as a function of the applied compression pressure and is presented in Eq. (3): 
$\ln \left(\frac{1}{1-\mathrm{D}}\right)=\mathrm{KP}+\mathrm{A} \ldots \ldots \ldots \ldots . . . \mathrm{Eq} \cdot 3$

where $D$ is the relative density of a compact, $K$ is the Heckel coefficient (slope of a linear part of the curve), $P$ is the applied compression pressure and $\mathrm{A}$ is the $y$-axis intercept. The onset of plastic deformation is defined as the Heckel yield pressure $\left(P_{Y}\right)$ and it is expressed as the reciprocal of the slope, $K$.

The Kawakita model ${ }^{29}(\mathrm{~b}$ describes the relationship between the degree of volume reduction of the powder and the applied pressure and is represented by Eq. 4 below:

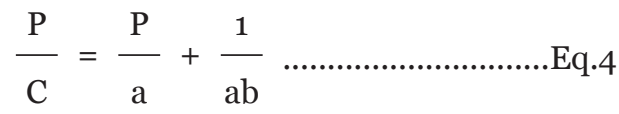

Where $C$ and $P$ represents the degree of volume reduction and compression pressure, respectively. The constant ' $a$ ' is the initial porosity of the material at the beginning of compression while the constant ' $b$ ' relates to the degree of plasticity of the material. The reciprocal of $b$ or $P_{K}$ defines the pressure required to reduce the powder bed by $50 \%$.

The porosity-pressure relationship, tensile strength-pressure relationship and tensile strength-porosity relationship representing compressibility, tabletability and compactibility (CTC) respectively were illustrated with plots generated based on the data obtained from compaction studies ${ }^{30-32}$.

\section{Tensile strength}

The breaking force required to crush tablets diametrically was measured using a tablet hardness tester (Erweka, USA). The dimensions of thickness and diameter for each tablet were measured using a digital calliper (Digimatic Mitutoyo Corporation, Japan) and fitted into Eq. 5 below to calculate tensile strength ${ }^{33}$.

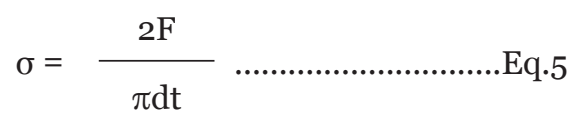

Where $\boldsymbol{\sigma}$ is the tensile strength $\left(\mathrm{MM} / \mathrm{m}^{2}\right), F$ is the breaking force $(\mathrm{N}), d$ is the diameter $(\mathrm{mm})$, and $t$ is the thickness of the tablet $(\mathrm{mm})$.

\section{RESULTS AND DISCUSSION}

There exists a relationship between the material attributes of an excipient and their functionality in drug product development. Solid-state properties, pow- 
der and mechanical properties of an excipient are known to predict its performance in formulation development ${ }^{7}$. Characterization of an excipient's properties is therefore necessary to identify its material attributes that will be a key consideration for its rational selection in drug formulation.

Optical and polarized images of TS and SGS are presented in Fig. 1 (A) - (D). The optical images appear spherical with the polarized images revealing a birefringent pattern (presence of a Maltese cross) consistent with the granular structure of native starches. This implies that co-processing did not affect the granular integrity of TS and hence gelatinization did not occur at the temperature employed for co-fusion. Gelatinization of TS occurs within the range of $55-70^{\circ} \mathrm{C}$ and is characterized by loss of birefringence (disappearance of the Maltese cross) and crystallinity ${ }^{34,35}$. Hence, the improvement in the functionality of SGS can be attributed to sub-particle level changes occurring as a result of co-processing TS with GEL and CSD and not to gelatinization of TS. The presence of these other excipients enmeshed in the particle structure of TS modulated its physicomechanical properties without necessary interfering with its granular structure. This confirms that co-processing as a particle engineering technique is entirely a physical process ${ }^{5,10}$ "

Particle size analysis carried out by microscopy revealed an increase in particle size of SGS relative to TS evidenced by the parameters, $d_{10}, d_{50}, \& d_{90}$ (Table 1 ). The median particle size $\left(d_{50}\right)$ of SGS was 2.4 times more than TS. The polydispersity index (PI) parameter was higher for SGS indicating a broader particle size distribution. Co-processing by co-fusion led to the agglomeration of the three excipients leading to particle size enlargement. Enhancement in the flowability profile of SGS has been linked to the increase in particle size. This outcome agrees with the findings of Adeoye and Alebiowu ${ }^{26,36}$ who developed a co-processed excipient using a similar method. It is necessary to control particle size of DC excipients as significant variation in size with the drug may lead to segregation during tableting 5,37 . 
Table 1. Particle size analysis of TS and SGS

\begin{tabular}{cccccc}
\hline & \multicolumn{5}{c}{ Particle size distribution } \\
\cline { 2 - 6 } Material & $\mathbf{D}_{10}(\mu \mathrm{m})$ & $\mathbf{D}_{50}(\mu \mathrm{m})$ & $\mathbf{D}_{90}(\mu \mathrm{m})$ & $\begin{array}{c}\text { Range } \\
(\mu \mathrm{m})\end{array}$ & $\begin{array}{c}\text { Polydispersity } \\
\text { index }(\mathrm{PI})\end{array}$ \\
\hline SGS & 15.5 & 29 & 57.8 & $6.3-110.9$ & 1.46 \\
TS & 8.9 & 12.3 & 16.8 & $5.6-25$ & 0.64 \\
\hline
\end{tabular}

TS - Tapioca starch SGS - Co-processed excipient

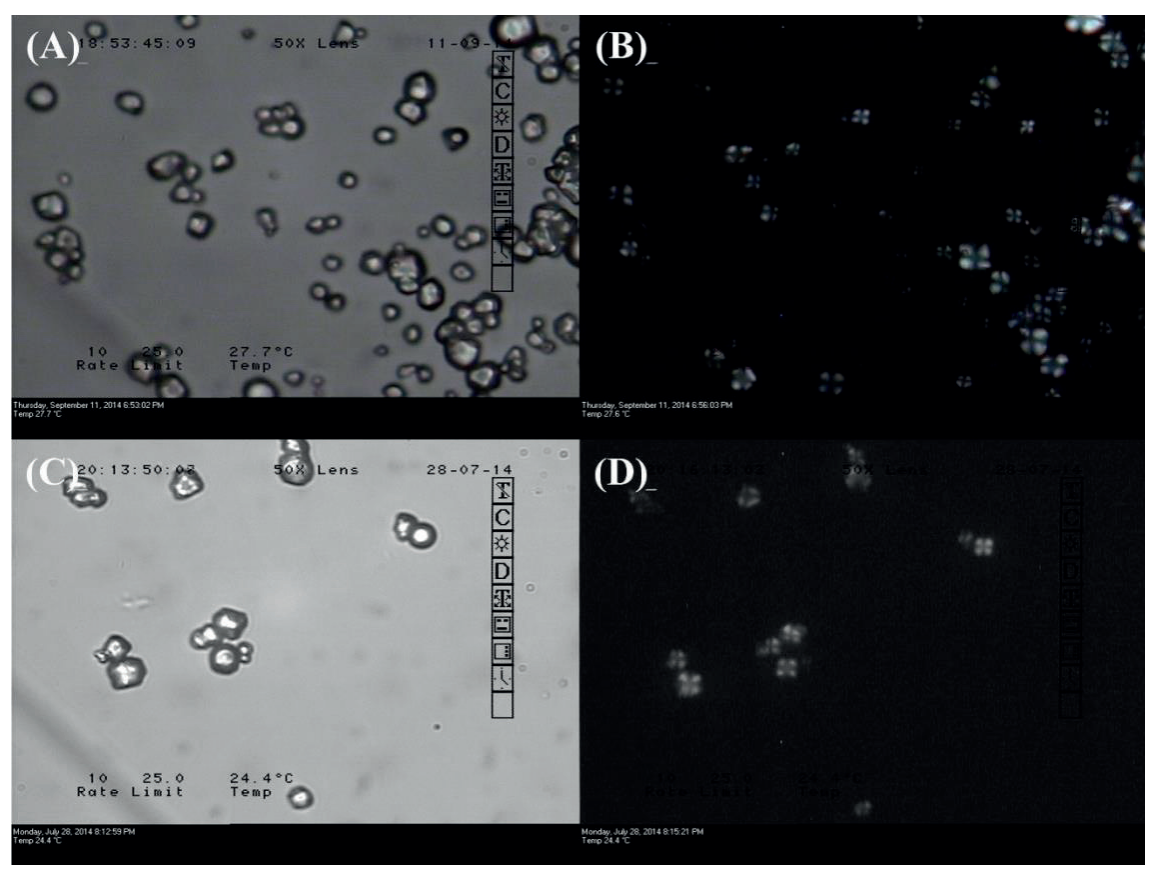

Figure 1. (A) Optical image of TS, (B) Polarized image of TS, (C) Optical image of SGS, (D) Polarized image of SGS. 
SEM images of SGS, TS, GEL and CSD are presented in Fig. 2 (A) - (D). Particle morphology of SGS revealed spherical shaped particles with slightly rough surfaces owing to the presence of GEL and CSD in the particle structure of TS. This agrees with the findings of Kittipongpatana and Kittipongpatana ${ }^{14}$ who attributed the rough surface morphology of co-processed rice starch and CSD to the homogeneous distribution of CSD on its surface. The surface roughness of SGS may have contributed to its improved tabletability profile when compared to its physical mixture (SGS-PM) due to increase in adhesion between bonding surfaces during compaction ${ }^{38-40}$ ". The spherical shape of SGS must have been derived to a large extent from TS as the major component of the co-processed excipient. This further explains the improvement in the flow properties of SGS considering the role particle shape plays in the flowability of materials ${ }^{15}$.
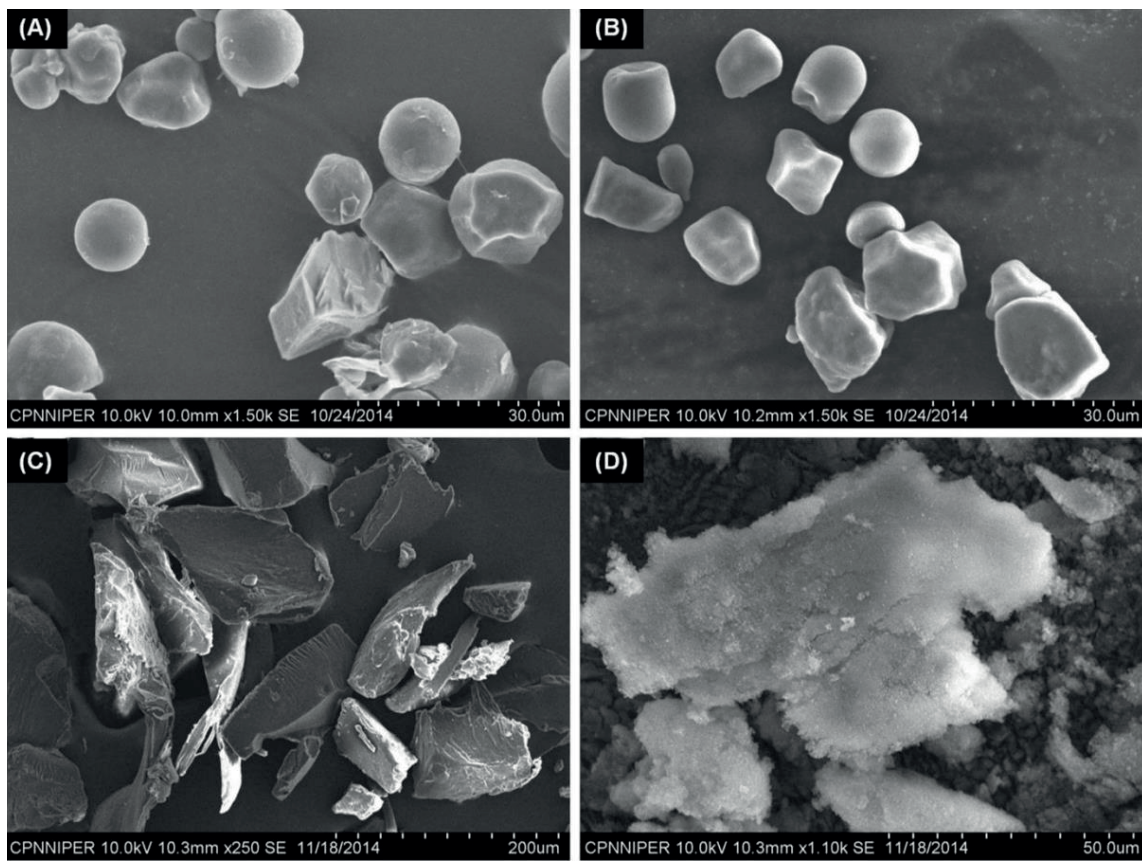

Figure 2. SEM images of (A) SGS, (B) TS, (C) GEL and (D) CSD

An overlay of the PXRD diffraction curves of the individual excipients (TS, GEL and CSD) and the co-processed excipient (SGS) is presented in Fig. 3A. The diffraction patterns of GEL and CSD were characterized by the absence of no peaks indicating that the material is non-crystalline. The diffraction curve of TS revealed a halo pattern which is consistent with amorphous polymers. The broad peaks observed in the diffraction pattern of TS showed that the ma- 
terial had some degree of crystallinity. A similar pattern was replicated in the diffraction curve of SGS implying that there was no significant chemical interaction occurring between the excipients during co-processing. PXRD patterns of SGS and SGS-PM displayed in Fig. 3B revealed a halo pattern consistent with amorphous materials ${ }^{16}$. The broad peak occurring at $2 \theta$ value of $13^{\circ}$ can be attributed to the semi-crystalline nature of starch. Consequently, the diffraction patterns of SGS and SGS-PM were superimposable indicating that coprocessing did not alter the molecular structure. The sharp diffraction peaks of ibuprofen confirm the crystalline nature of the drug (Fig. $3 \mathrm{C}$ ). These peaks were maintained in the powder mix of IBU and SGS indicating drug-excipient compatibility.
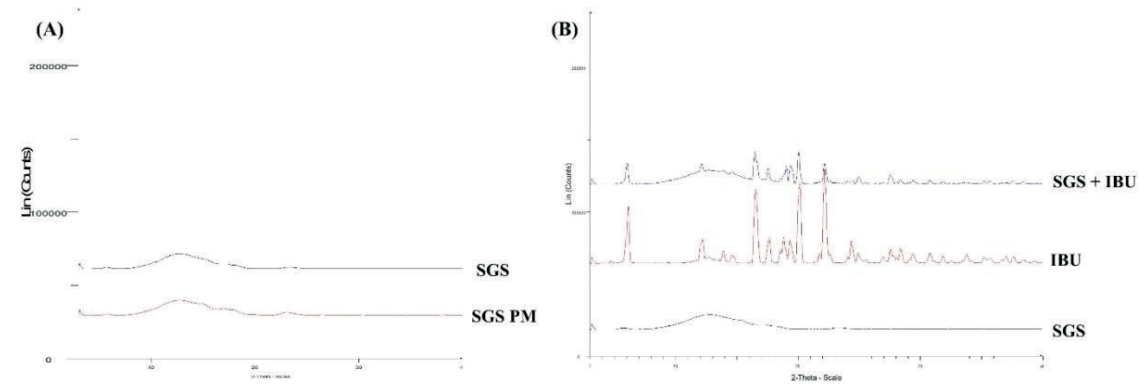

Figure 3. PXRD of (A) SGS and SGS-PM (B) SGS, IBU and SGS + IBU

The FT-IR spectra of SGS, IBU and SGS+IBU are presented as an overlay plot in Fig. 4. The IR spectrum of SGS showed characteristic peaks at 2934, 1636, $1416,1337,1150$ and $998.6 \mathrm{~cm}^{-1}$ corresponding to $\mathrm{C}-\mathrm{H}$ aliphatic stretch, $\mathrm{NH}$ bend, $\mathrm{C}-\mathrm{N}$ stretch, $\mathrm{C}-\mathrm{O}$ stretch and $\mathrm{C}=\mathrm{H}$ bend respectively. The IR spectrum of IBU was characterized by vibrations occurring at $3630 \mathrm{~cm}^{-1}(\mathrm{OH}$ stretch), 3088, $2954 \mathrm{~cm}^{-1}$ (C-H stretch), $1707 \mathrm{~cm}^{-1}$ (C=O stretch), and $1183 \mathrm{~cm}^{-1}$ (C-O stretch) (Fig. $5 \mathrm{C}$ ). These peaks were retained in the IR spectrum of a blend of IBU and SGS suggesting that both materials are compatible. Although, changes in the intensity of peaks were observed as a result of dilution effect, the position of these peaks was maintained without a significant shift. Drug-excipient compatibility was therefore confirmed with IR studies. 


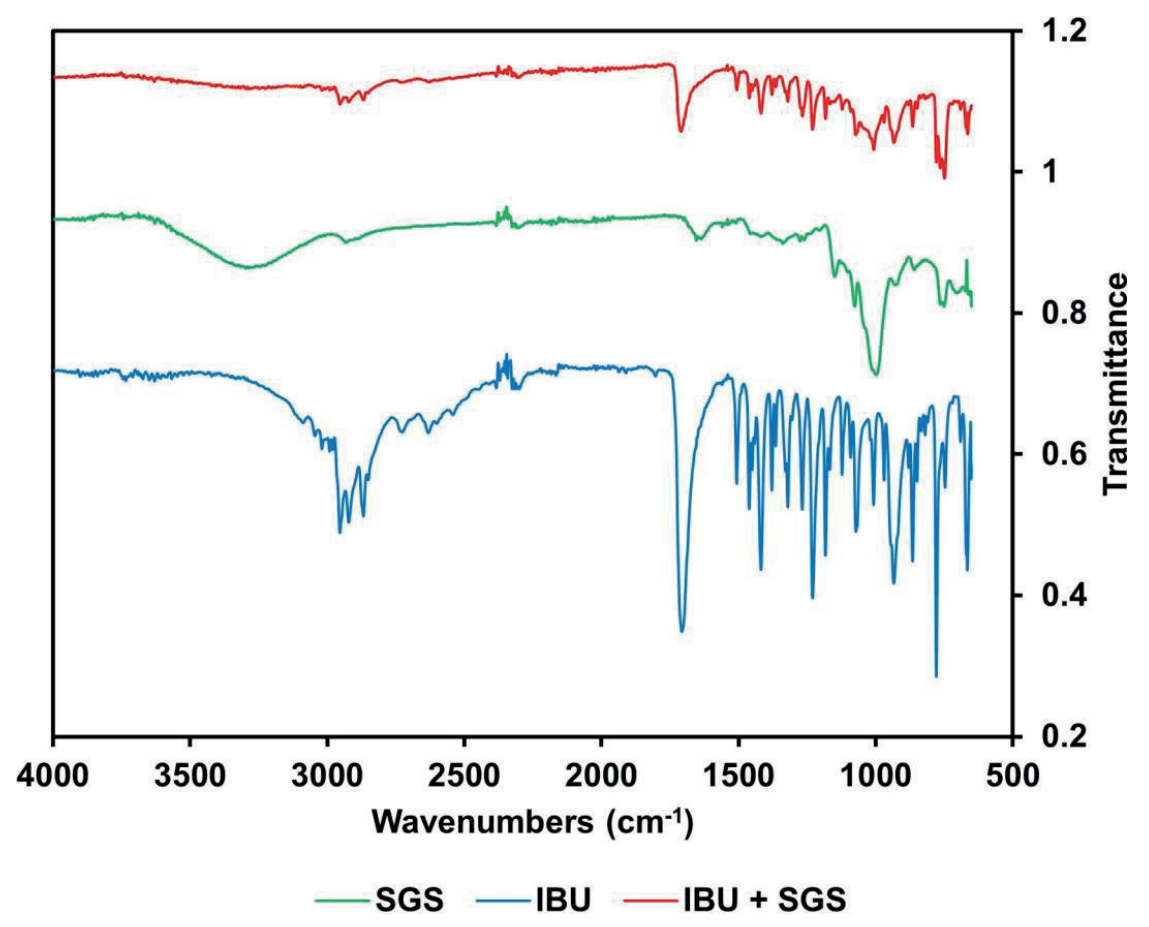

Figure 4. FT-IR overlay of SGS, IBU and SGS+IBU

Table 2 summarizes the powder properties of TS, SGS and SGS-PM. Measurement of angle of repose was used to estimate the flow behaviour of the investigated powders. Values were reported only for SGS as it was not possible to measure the angle of repose of TS and SGS-PM due to poor flowability. The value reported for SGS was $21.6^{\circ}$ which is an indication of a free-flowing powder. Other parameters measured to estimate powder flow for all three materials were CI and HR which ranged from $14.7-23.2 \%$ and $1.17-1.30$ respectively with SGS having the least values for both parameters. CI and HR parameters of SGS were consistent with the angle of repose as they met the requirements for good flow properties ( $\mathrm{CI}<20 \%$ and $\mathrm{HR}<1.2)^{15}$ roundness, irregularity, equivalent circle diameter (ECD. These parameters give an indirect estimate of the flow behaviour of a material as they measure the degree of packing or consolidation of a powder based on the bulk and tapped densities. 
Table 2. Powder properties of TS, SGS and SGS-PM $(n=3)$

\begin{tabular}{cccc}
\hline Properties & TS & SGS & SGS-PM \\
\hline Angle of repose $\left({ }^{\circ}\right)$ & Not passable & $21.6(0.29)^{*}$ & Not passable \\
Bulk density $\left(\mathrm{g} / \mathrm{cm}^{3}\right)$ & $0.51(0.02)$ & $0.48(0.01)$ & $0.54(0.02)$ \\
Tapped density $(\mathrm{g} /$ & $0.65(0.02)$ & $0.57(0.02)$ & $0.70(0.03)$ \\
$\left.\mathrm{cm}^{3}\right)$ & $22(2.64)$ & $14.7(2.34)$ & $23.2(2.76)$ \\
Carr's index $(\%)$ & $1.28(0.04)$ & $1.17(0.03)$ & $1.30(0.05)$ \\
Hausner's ratio & 66.5 & 66.6 & 63.3 \\
Porosity $(\%)$ & $1.52(0.02)$ & $1.45(0.02)$ & $1.46(0.01)$ \\
True density & & & \\
\hline
\end{tabular}

* The values in parentheses represent standard, TS - Tapioca starch, SGS - Co-processed excipient

SGS-PM - Physical mixture of the component excipients of the co-processed excipient in similar proportion

Powder flow is critical to the success of tablet formulation by direct compression. Majority of excipients considered for direct compression are required to impart flowability to the powder blend of the drug and excipient to prevent a wide variation in weight and content uniformity of tablets. One outstanding attribute of co-processed excipients is improved flowability. The study has shown an improvement in the flow functionality of SGS based on AR, CI and HR. Lower values for all three parameters corresponds to better flow properties. It was not possible to measure the angle of repose of TS and SGS-PM because the because of increased interparticulate friction existing between particles of small sizes. The mechanism by which flowability of SGS was improved by co-processing can be attributed to the increase in particle size and porosity giving particles ample space to flow easily. The lower the degree of packing of a powder, the better the flow output of the powder. Hence, powders that are more porous will flow faster compared to less porous powders as confirmed by the bulk and tapped densities of SGS (Table 2) which were relatively low compared to TS and SGS-PM. The improvement in flow properties of SGS as a result of co-processing agrees with the trend observed by other studies performed in the development of co-processed excipients ${ }^{13-15,26,41}$

The Heckel and Kawakita parameters describing the mechanical properties of SGS and SGS-PM are presented in Table 3. 
Table 3. Heckel and Kawakita Parameters of SGS and SGS-PM

\begin{tabular}{ccccccccc}
\hline & \multicolumn{3}{c}{ Heckel } & \multicolumn{5}{c}{ Kawakita } \\
\cline { 2 - 8 } Material & $\mathrm{P}_{\mathrm{Y}}(\mathrm{MPa})$ & $\mathrm{D}_{\mathrm{A}}$ & $\mathrm{D}_{0}$ & $\mathrm{D}_{\mathrm{B}}$ & $\mathrm{a}$ & $\mathrm{b}$ & $\mathrm{P}_{\mathrm{K}}$ \\
& & & & & & & \\
\hline SGS & 243.90 & 0.803 & 0.393 & 0.410 & 0.659 & 0.159 & 6.299 \\
SGS-PM & 285.71 & 0.736 & 0.479 & 0.257 & 0.607 & 0.090 & 11.077 \\
\hline
\end{tabular}

SGS - Co-processed excipient, SGS-PM - Physical mixture of the component excipients of the co-processed excipient in similar proportion

The pressure at which deformation was initiated during compaction corresponds to the mean yield pressure $\left(P_{Y}\right)$ computed as the inverse of the slope of the linear portion of the Heckel plot (Fig. 5A). The $P_{Y}$ of SGS was lower than that of SGS-PM indicating that a faster onset of plastic deformation had occurred during compression. Lower values of $P_{Y}$ implies that the material is soft, ductile and readily undergoes plastic deformation while higher values have been implicated in materials that are hard, brittle and resistant to plastic deformation. A lower yield pressure was obtained for SGS relative to SGS-PM implying that it is more compressible and less resistant to deformation during compression into compacts. This may be attributed to the insertion of GEL and CSD into the particle structure of TS which influenced its deformation behaviour giving rise to a material that is more compressible and deforms at a lower yield pressure. The total degree of powder consolidation at the beginning of compression $\left(D_{A}\right)$ was seen to be higher for SGS compared to SGS-PM. This can be attributed to the high degree of particle fragmentation occurring with SGS during compression as evidenced by its high $D_{B}$ value. Particle fracture at the early stages of compression leads to the generation of smaller particles which rearrange to fit into the pore spaces resulting in a highly consolidated powder bed ${ }^{42}$. The extent of powder consolidation occurring as a result of initial particle rearrangement due to particle movement $\left(D_{o}\right)$ was lower for SGS compared to SGS-PM suggesting that particle fragmentation $\left(D_{B}\right)$ was the major contributor to the total degree of powder consolidation.

The $P_{K}$ parameter resolved from the Kawakita plot (Fig. $5 \mathrm{~B}$ ) is a measure of the pressure required to contract the volume of the powder bed by $50 \%$ during compaction. A lower value was obtained for SGS in comparison to SGS-PM 
indicating a faster onset of compression. The ' $a$ ' parameter which is a measure of compressibility was higher for SGS compared to SGS-PM. Similarly, the ' $b$ ' parameter which corresponds to the total amount of plastic deformation occurring in the powder during compaction was higher for SGS compared to its physical mixture, SGS-PM. The $P_{K}$ value which represents the compression effort needed to consolidate the powders to $50 \%$ of its initial volume was found to be lower for SGS when compared to its physical mixture, SGS-PM. Overall, the findings of Kawakita analysis is consistent with the observations of the Heckel analysis.

(A)

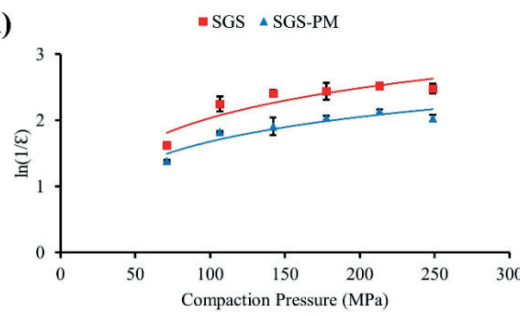

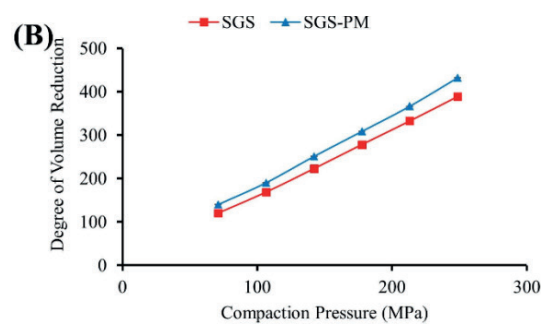

Figure 5. (A) Heckel Plot and (B) Kawakita Plot

The CTC (compressibility, tabletability and compactibility) profile of SGS and SGS-PM is illustrated in Fig. 6A-C. The compressibility plot (Fig. 6A) of the two materials reveals a decrease in the porosity of the compact as the compaction pressure increases. It was observed that the porosity of compacts for both materials did not change significantly beyond $100 \mathrm{MPa}$. The porosity of SGS compacts were found to be lower when compared to those of SGS-PM at the same compaction pressure implying a greater degree of compressibility in SGS. Compressibility refers to the ability of a powder to undergo volume reduction under the effect of applied pressure and is represented by a porositypressure relationship ${ }^{31,32}$

The porosities of SGS compacts were significantly lower than those of SGS-PM across the range of pressures employed implying a greater degree of compressibility. There was an increased capacity for volume reduction during compression of SGS possibly due to the presence of CSD which has been used as a compressibility enhancing agent ${ }^{17,24}$. The presence of GEL in the particle structure of SGS is more likely to have contributed to its compressibility because of its role as a binder which improves the cohesiveness of powder particles during compression thereby lowering the porosity with a corresponding increase in relative density (solid fraction) of the compact. The effect of reduction in po- 
rosity during compression brings particles in close proximity thereby increasing the area available for bonding. Compressibility of an excipient therefore plays a significant role in the formation of tablets.
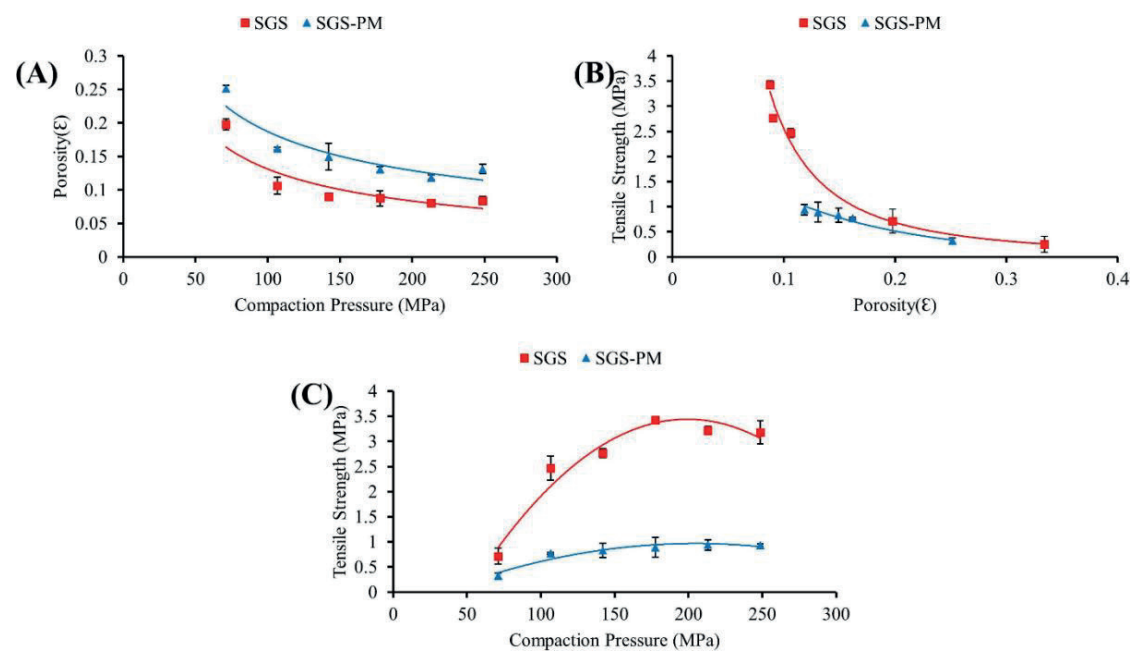

Figure 6. (A) Compressibility plot, (B) Compactibility plot and (C) Tabletability plot.

The compactibility plot illustrated in Fig. 6B demonstrated a pattern of increasing tensile strength of compacts with decrease in porosity for both materials. Compacts of higher tensile strength at the same level of porosity were obtained with SGS in comparison to SGS-PM. Compactibility refers to the ability of a material to form compacts of sufficient mechanical strength and is depicted by tensile strength-porosity relationship ${ }^{30,31}$. For the successful formation of tablets during compression, bonds must be formed between neighbouring particles to convert the loose powder bed into a solid compact. The degree of compactibility of SGS was significantly higher than that of SGS-PM as the tensile strength of SGS compacts produced at the same level of porosity was twice the value obtained with SGS-PM. Hence, there was an improvement in the compactibility of SGS as a result of co-processing leading to an increased bonding strength per unit area.

The tabletability profile of the two materials depicted in Fig. 6C shows the effect of compaction pressure on tensile strength of compacts. There was a corresponding increase in tensile strength of compacts for both materials as the applied pressure increased. The tensile strength of SGS compacts was found to be higher than that of SGS-PM at the same compression pressure. Maximum tensile strength obtained for SGS compacts was 3 MPa compared to less than 1 
MPa for SGS-PM at a compaction pressure of $250 \mathrm{MPa}$. The combined effect of compressibility (bonding area) and compactibility (bonding strength per unit area) must have resulted in the improved tabletability observed with SGS over SGS-PM. Tabletability is the capacity of a powdered material to be transformed into a tablet of specified strength under the effect of compaction pressure ${ }^{31,40}$. The improved tabletability of SGS may have been attributed to its ability to overcome the elastic recovery stage occurring during decompression thereby retaining to a large degree the strength of interparticulate bonds formed during compression. Materials with high particle fragmentation tendency are not prone to immediate elastic recovery because of the minimal elastic energy that is stored during compression ${ }^{43}$. Hence, the combined mechanisms of bonding area and bonding strength (BABS) is necessary for the successful formation of tablets ${ }^{39,40}$. The material attributes of a co-processed excipient (SGS) developed by co-fusion were characterized and found to be suitable for tableting applications in comparison to its parent excipient (TS) and physical mixture (SGS-PM).

\section{REFERENCES}

1. Camargo, J. J. R. Assessment of co-processing of cellulose II and silicon dioxide as a platform to enhance excipient functionality. PhD Thesis, University of Iowa, 2011.

2. Odeku. O. A. Potentials of tropical starches as pharmaceutical excipients: A review. Starch/ Staerke, 2013, 65, 89-106.

3. Emeje, M. O.; Asha, R. Starch. from food to medicine. In: Valdez B, editor. Scientific, Health and Social Aspects of the Food Industry. Online, Shanghai, China: InTech China; 2012, p. $355-380$.

4. Rashid, I.; Al-Omari, M. M. H.; Badwan A. A. From native to multifunctional starch-based excipients designed for direct compression formulation. Starch/Starke, 2013, 65(Dc), 552-571.

5. Nachaegari, S. K.; Bansal, A. K. Coprocessed Excipients for Solid Dosage Forms. Pharm. Technol. 2004, (January), 52-64.

6. Rojas, J.; Aristizabal, J.; Henao, M. Screening of several excipients for direct compression of tablets: A new perspective based on functional properties. J. Basic Appl. Pharm. Sci. 2013, $34,17-23$.

7. Sun, C. C. Materials Science Tetrahedron-A Useful Tool for Pharmaceutical Research and Development. J. Pharm. Sci. 2009, 98, 1671-1687.

8. Zhou, D.; Qiu, Y. Understanding Material Properties in Pharmaceutical Product Development and Manufacturing: Powder Flow and Mechanical Properties. J. Valid. Technol. 2010, 65-77.

9. Saha, S.; Shahiwala, A. F. Multifunctional coprocessed excipients for improved tabletting performance. Expert Opin. Drug Deliv. 2009, 6, 197-208.

10. Rojas, J.; Buckner, I.; Kumar, V. Co-processed excipients with enhanced direct compression functionality for improved tableting performance. Drug Dev. Ind. Pharm. 2012, 38, 1159-1170.

11. Daraghmeh, N.; Chowdhry, B.; Leharne, S.; Omari, M.; Badwan, A. Co-Processed Chitin- 
Mannitol as a New Excipient for Oro-Dispersible Tablets. Mar. Drugs, 2015, 13, 1739-1764.

12. Mshelia, J.; Apeji, Y.; Olayemi, O. Powder, Compaction and Tableting Properties of Coprocessed Silicified Starch. Br. J. Pharm. Res. 2015, 6, 131-140.

13. Daraghmeh, N.; Rashid, I.; Al Omari, M. M. H.; Leharne, S. A.; Chowdhry, B. Z.; Badwan, A. Preparation and characterization of a novel co-processed excipient of chitin and crystalline mannitol. AAPS PharmSciTech, 2010, 11, 1558-1571.

14. Kittipongpatana, O. S.; Kittipongpatana, N. Preparation and physicomechanical properties of co-precipitated rice starch-colloidal silicon dioxide. Powder Technol, 2011, 217, 377-382.

15. Ogunjimi, A. T.; Alebiowu, G. Flow and consolidation properties of neem gum coprocessed with two pharmaceutical excipients. Powder Technol, 2013, 246, 187-192.

16. Sharma, P.; Modi, S. R.; Bansal, A. K. Co-processing of hydroxypropyl methylcellulose (HPMC) for improved aqueous dispersibility. Int J Pharm, 2015, 485, 348-356.

17. Rojas, J.; Kumar, V. Comparative evaluation of silicified microcrystalline cellulose II as a direct compression vehicle. Int J Pharm, 2011, 416, 120-128.

18. Odeku, O. A.; Schmid, W.; Picker-Freyer, K. M. Material and tablet properties of pregelatinized (thermally modified) Dioscorea starches. Eur J Pharm Biopharm 2oo8, 70, 357-371.

19. Jonat, S.; Albers, P.; Gray, A.; Schmidt, P. C. Investigation of the glidant properties of compacted colloidal silicon dioxide by angle of repose and X-ray photoelectron spectroscopy. Eur $J$ Pharm Biopharm 2006, 63, 356-359.

20. Jonat, S. The mechanism of hydrophilic and hydrophobic colloidal silicon dioxide types as glidants. PhD Thesis, Eberhard-Karls-Universität Tübingen, 2005.

21. Tobyn, M. Physicochemical comparison between microcrystalline cellulose and silicified microcrystalline cellulose. Int J Pharm 1998, 169, 183-194.

22. Edge, S.; Steele, D. F.; Chen, A.; Tobyn, M. J.; Staniforth, J. N. The mechanical properties of compacts of microcrystalline cellulose and silicified microcrystalline cellulose. Int $J$ Pharm 2000, 200, 67-72.

23. Majerová, D.; Kulaviak, L.; Růžička, M.; Štěpánek, F.; Zámostný, P. Effect of colloidal silica on rheological properties of common pharmaceutical excipients. Eur $J$ Pharm Biopharm. 2016, 106, 2-8.

24. Arora, V.; Gupta, V. B.; Singhal, R. Advances in direct compression technology. Pharma Times 2007, 39, 26-27.

25. Iyali, J. M. Cassava : Nigeria's untapped Goldmine. Freedom Radio Nigeria. Available from: http://www.freedomradionig.com/index.php/39-icetheme/editorials/403-cassava-nigeria-suntapped-goldmine [accessed January 1, 2014].

26. Adeoye, O.; Alebiowu, G. Flow, packing and compaction properties of novel coprocessed multifunctional directly compressible excipients prepared from tapioca starch and mannitol. Pharm Dev Technol 2014, 19, 901-910.

27. United States Pharmacopoeial Convention. USP Protocol for bulk and tapped densities. $U S P / N F, 2012$.

28. Heckel, R. W. Density-Pressure Relationships in Powder Compaction. Trans Metall Soc AIME 1961, 221, 671-675.

29. Kawakita, K.; Lüdde, K. H. Some considerations on powder compression equations. Powder Technol 1971, 4, 61-68. 
30. Upadhyay, P.; Khomane, K. S.; Kumar, L.; Bansal, A. K. Relationship between crystal structure and mechanical properties of ranitidine hydrochloride polymorphs. Cryst. Eng. Comm. 2013, 15, 3959-3964.

31. Joiris, E.; Di Martino, P.; Berneron, C.; Guyot-Hermann, A.; Guyot, J. Compression Behavior of Orthorhombic Paracetamol. Pharm Res 1998, 15, 1122-1130.

32. Khomane, K. S.; More, P. K.; Raghavendra, G.; Bansal, A. K. Molecular understanding of the compaction behavior of indomethacin polymorphs. Mol. Pharm. 2013, 10, 631-639.

33. Fell, J.; Newton, J. Determination of tablet strength by the diametral-compression test. $J$ Pharm Sci 1970, 59, 688-691.

34. Sullivan, J. W.; Johnson, J. A. Measurement of starch gelatinization by enzyme susceptibility. Cereal. Chem. 1964, 41, 73-79.

35. Gomand, S. V.; Lamberts, L.; Derde, L. J.; Goesaert, H.; Vandeputte, G. E.; Goderis B. Structural properties and gelatinisation characteristics of potato and cassava starches and mutants thereof. Food. Hydrocoll. 2010, 24, 307-317.

36. Adeoye, O.; Alebiowu, G. Evaluation of co-processed disintegrants produced from tapioca starch and mannitol in orally disintegrating paracetamol tablets. Acta Pol Pharm ñ Drug Res, 2014, $71,803-811$.

37. Mînea, L. A.; Mehta, R.; Kallam, M.; Farina, J. A.; Deorkar, N. Evaluation and Characteristics of a New Direct Compression Performance Excipient. Pharm Technol 2011, 35, 1-8.

38. Osei-Yeboah, F.; Sun, C. C. Tabletability Modulation Through Surface Engineering. $J$ Pharm Sci 2015, 104, 2645-2648.

39. Osei-Yeboah, F.; Chang, S.; Sun, C. C. A critical Examination of the Phenomenon of Bonding Area - Bonding Strength Interplay in Powder Tableting. Pharm. Res. 2016, 33, 1126-1132.

40. Sun, C. C. Decoding Powder Tabletability: Roles of Particle Adhesion and Plasticity. J Adhes Sci Technol 2011, 25, 483-499.

41. Chauhan, S. I.; Nathwani, S. V.; Soniwala, M. M.; Chavda, J. R. Development and Characterization of Multifunctional Directly Compressible Co-processed Excipient by Spray Drying Method. AAPS PharmSciTech 2017, 18, 1293-1301.

42. Apeji, Y. E.; Aluga, D.; Olayemi, O.; Oparaeche, C.; Anyebe, S.; Gamlen, M.; Oyi, A. R. Comparative analysis of co-processed starches developed by three different methods. Br J Pharm 2017, 2, 1-15.

43. Zhang, J.; Wu, C. Y.; Pan, X.; Wu, C. On identification of critical material attributes for compression behaviour of pharmaceutical diluent powders. Materials (Basel) 2017, 1O, 1-16. 